\title{
Asbestos amphiboles: effects of comminution on tremolite and actinolite regulated and unregulated fibres
}

\author{
Department of Earth, Environment and Life Sciences (DISTAV), University of Genoa, Italy; *Corresponding author, E-mail: gaiamaria. \\ militello@edu.unige.it
}

(Received: January 31, 2020; Revised accepted: July 21, 2020)

https://doi.org/10.18814/epiiugs/2020/0200s09

Crocidolite, amosite, anthophyllite, tremolite, actinolite besides the chrysotile serpentine polymorph fall within the classification of asbestos, whose commercial use is banned, and environmental and human exposure levels regulated. However, the cited amphibole species can crystallise in asbestiform or non-asbestiform habit and therefore their morphological characterization has a key role in assessing a reliable asbestos hazard scenario. Furthermore, when a mechanical stress is applied to rocks containing pristine prismatic or acicular amphiboles, these phases can break, originating particles with dimensions and geometrical ratios that would label them as asbestos. Therefore, a normative and scientific crucial gap arise in the classification criteria of a particle as a real asbestiform mineral or as a cleavage fragment (i.e. non-asbestos). The mode of comminution is fundamental for the following quantitative determination of fibres. It is critical because it can affect the morphology and geometric ratios of fibres, inducing positive or negative falses. In this framework, our work was focused on the Scanning Electron Microscopy coupled with Energy Dispersive Spettroscopy (SEM-EDS) analysis of amphiboles with asbestiform and non-asbestiform habit, subject to mechanical stress for three different time intervals, in order to assess how different time lengths of comminution control geometry and morphology of the particles.

\section{Introduction}

The evaluation of the asbestos hazard (Gaggero et al., 2017) is based on counting criteria used to determine the amount of regulated fibres (Belardi et al., 2018). Nevertheless, different procedures were proposed for refining the classification of particles as asbestos or fibres originated by preferential cleavage of particles (Wylie et al., 1985; Ahera, 1987; Osha 1994a, 1994b; Harper et al., 2008, 2012; Van Orden et al., 2008, 2009; Niosh, 2011). Official survey techniques prescribed by the normative for the assessment of the presence of asbestos, by qualitative and quantitative analysis of excavated soils and rocks, do not guarantee a unique and reproducible quantification of asbestos con- tent (Militello et al., 2019a), especially if the phases belong to the group of asbestos by composition, but not necessarily by morphology. This is caused by the limits of the Italian protocols that do not prescribe univocally the preparation and the analysis of the samples, thus originating variability in the results.

Whereas the asbestiform amphiboles have been clearly identified and banned, acicular/prismatic amphibole crystals are not univocally regulated as asbestos, although their geometric ratios often fit the definition of fibre. Under similar chemical composition, the morphological characterization of the phases cannot be disregarded, if the aim is the quantification of fibres and consequently their carcinogenicity. Moreover, non-asbestiform particles are a potentially major source of exposure all over the world and therefore adverse health effects may derive (Hwang et al., 2014).

A worldwide normative and scientific gap concerns the classification criteria of the asbestos, that is in fact mainly referred to the asbestiform and non-asbestiform varieties of the amphiboles group, as mentioned above. Asbestiform amphibole can have neat fibrous and asbestiform habit, whereas its non-asbestiform analogue can derive from size reduction of a pristine prismatic/acicular mineral with dimensions and geometrical ratio (length $>5 \mu \mathrm{m}$, diameter $<3 \mu \mathrm{m}$, and length to width ratio $\geq 3: 1$ ) that would in the count make it classifiable as fibrous. The non-asbestiform, in fact, can develop a prismatic or fibrous habit, characterized by a parallel growth of elongated crystals, having nanometric width and micrometric length (Harper et al., 2012). Also among serpentine polymorphs, the fibrous antigorite is very similar in morphology to the polymorph chrysotile and therefore the two are not easily distinguishable, especially if associated.

In sample preparation, comminution is a fundamental step for the subsequent quantitative determination of fibres, as it can affect the variability of the geometric and morphological relationships of particles. However, preparation methods described in the Italian Ministerial Decree (M.D. 06/09/1994), but also in other ministerial protocols, from other countries, lack of precise coding, thus not guaranteeing comparable and reproducible intra- and inter-laboratory results. For Ham et al. (2019 and references therein), quantitative analysis and the accuracy of the results depend also on the experience of the analyst. As a consequence, quantitative calculations can produce high variance results, inhibiting a risk assessment based on univocal data (Militello et al., 2019b). As already demonstrated, when a mechanical stress (such as 
grinding) is applied to rocks containing non-asbestiform amphiboles, they can break, originating particles of different lengths but still with dimensions and geometric ratios that make them included in asbestos. The consequence on the recast of concentration takes thus to false positives or false negatives, generating a critical issue.

The present investigation focused on the observation by SEM-EDS over a statistically significant population of samples containing tremolite-actinolite amphiboles with asbestiform and non-asbestiform habit. The samples were subject to mechanical stress for three different time intervals, in order to observe how the geometry and the morphology of the particles varied according to the duration of comminution.

\section{Diversity in Asbestos Definition and Grinding Approaches}

\section{Asbestos Definition}

The generic term asbestos is referred to a group of six natural minerals represented by easily separable hydrated silicates in thin, flexible fibres, resistant to traction or heat and chemically inert. The minerals defined as asbestos include the asbestiform varieties of the serpentine (chrysotile and fibrous antigorite), cummingtonite-grunerite (amosite) and tremolite and actinolite series, riebeckite (crocidolite), and anthophyllite.

The term "asbestos" has both a mineralogical and a commercial use, that in time caused misunderstandings. Key words and debated items among the scientific community are the following:

Fibrous, term linked to the geometry of the particles according to the World Health Organization (WHO, 1997). Fibres must have length $>5 \mu \mathrm{m}$, diameter $<3 \mu \mathrm{m}$, with a defined aspect ratio (length of the particles divided by the width, $A / R$ ) of $\geq 3: 1$. However, to some members of the scientific community, any mineral very thin and long, with a high aspect ratio can be called fibrous (Gualtieri, 2017 and references within).

Asbestiform, refers to a specific type of mineral fibrosity in which the fibrils possess high tensile strength or flexibility.

In the national and international regulatory framework, there are mainly two opposite concepts of classification, and therefore variable concern about the particles:

- The National Institute for Occupational Safety and Health (NIOSH), Occupational safety and Health Administration (OSHA), WHO and the USA Environmental Protection Agency (EPA), are in favour of including cleavage fragments within fibre counts taking into account length and diameter.

Cleavage fragments refers to amphibole or serpentine minerals that despite having the same chemical composition as asbestos minerals, are not classified as such. In geometrical ratios they would fall within the concept of fibre, although they are not asbestiform.

- The American Society for Testing and Materials (ASTM) classifies as "potentially asbestiform" only those mineral phases whose appearance meets specific characteristics as those described by NIOSH and length $>10 \mu \mathrm{m}$ or width $<1 \mu \mathrm{m}$ (Harper et al., 2008, 2012).

Subsequently, NIOSH has proposed the use of the term Elongate Mineral Particles (EMP) to refer to mineral particles with a length $\geq 5 \mu \mathrm{m}$ and a minimum aspect ratio of 3:1 that correspond to breathable size
Table 1. Counting criteria adopted by some authors for asbestos identification procedures. Modified from Belardi et al. (2018)

\begin{tabular}{cc}
\hline \hline Reference & Single particle \\
\hline Stanton et al. (1981) & Length $>8 \mu \mathrm{m}$ \\
& Diameter $<0.25 \mu \mathrm{m}$ \\
AHERA method (1987) & $\mathrm{A} / \mathrm{R} \geq 5: 1$ \\
EPA (1993) & $\mathrm{A} / \mathrm{R} 20: 1-100: 1$ \\
Berman and Crump (2003) & Length $>10 \mu \mathrm{m}$ \\
& Diameter $<0.4 \mu \mathrm{m}$ \\
Harris et al. (2007) & $\mathrm{A} / \mathrm{R}>25: 1$ \\
& Diameter $<0.5 \mu \mathrm{m}$ \\
Chatfield (2008) & $\mathrm{A} / \mathrm{R} 20: 1-100: 1$ \\
Van Orden et al. (2008; 2009) & Diameter $1.5 \mu \mathrm{m}, \mathrm{A} / \mathrm{R}>20: 1$ \\
Harper et al. (2012) & $\mathrm{A} / \mathrm{R}>5: 1$ \\
\hline
\end{tabular}

(Williams et al., 2013), avoiding the use of the term fibre which leads to characterization misunderstandings. The current regulations for asbestiform EMP are based on the NIOSH Method 7400, a counting protocol that however has been criticized as lacking a scientific background (Hwang et al., 2014). Herein, amphibole minerals with nonasbestiform habit, when length $>5 \mu \mathrm{m}$ and aspect ratio $\geq 3: 1$ are included (Gualtieri, 2017 and references therein).

This overview evidences how confusing are indications and, moreover, that the definition lacks standardized operating definitions for fibres (Keane et al., 1999). Table 1 lists only some of the asbestos counting criteria used by the world scientific community.

Stanton et al. (1981) correlated the asbestos hazard to the occurrence of EMP having size $>8 \mu \mathrm{m}$ in length $<0.25 \mu \mathrm{m}$ in diameter. The AHERA method (Asbestos Hazardous Emergency Response Act) suggests considering a 5:1 as the minimum aspect ratio. To report further examples, EPA (1993) method notes that the mean aspect ratios for asbestiform fibres range from 20:1 to 100:1 or higher. Cleavage fragments of the same phases are generally characterised by shorter aspect ratios of 20:1 or less. Berman and Crump (2003) proposed a hazard scenario by considering particles longer than $10 \mu \mathrm{m}$ and thinner than $0.4 \mu \mathrm{m}$ (A/R > 25:1). Harris et al. (2007) clearly assess the difference between fibres and acicular particles. The first are thin particles (width $\leq 0.5$ $\mu \mathrm{m})$ with parallel sides, smooth surfaces, and no discernible crystal faces, very high (20:1 to 100:1, or higher) aspect ratios and often displaying curvature. Conversely, the second are thin particles (width $\leq 0.5 \mu \mathrm{m})$ with generally moderate (10:1 to $20: 1)$ to high $(>20: 1)$ aspect ratios and developing crystal faces. Applying the Chatfield (2008) procedure, all particles thinner than $1.5 \mu \mathrm{m}$ and having A.R. exceeding 20:1 would be classified as asbestos. Van Orden et al. $(2008,2009)$ proposed a multidisciplinary procedure to differentiate asbestos from non-asbestos amphibole by integrating chemical and morphological features at the scale of Transmission Electron Microscopy (TEM). Finally, the method introduced by Harper et al. (2012) is based on microscopic measurements and includes all EMP showing width below $1 \mu \mathrm{m}$ (Belardi et al., 2018).

Aspect ratio is therefore the main feature used to differentiate asbestiform fibres from cleavage fragment. Several minimum values of aspect ratio have been suggested, ranging from 3:1 to 5:1 to $20: 1$ or greater. Wylie et al. (1993) showed that the average aspect ratio in 
asbestos fibres is 8-10 times greater than in non-asbestos particles.

Currently, no agreement is achieved on the bearing of making such a distinction. Some authors believe fibres with length less than $5 \mu \mathrm{m}$ are to be considered hazardous as well. Since the research is clear on the length of fibres that need monitoring, it would seem prudent to include all size fractions above $0.5 \mu \mathrm{m}$ of width. This will provide data that will perhaps allow future research to better decide which size categories contribute to risk (Vallero et al., 2009).

\section{Comminution Methods}

Mechanical comminution is the reduction of solid materials from an average particle size to a smaller average size. Size distribution and shape of the final products depend on the original size and nature of the minerals, but also depend on grinding conditions and type of mill.

The type and duration of grinding, controlled by rock hardness, can deeply transform the material itself by changing the size, and hence the number of fibres that are counted under microscopy (Cavariani et al., 2010) as well as their pristine crystallinity (Bloise et al., 2018).

In addition, no worldwide regulation suggests what instrument should be used to grind the samples (also depending on the lithotype), to be subsequently analysed to quantify the presence of asbestos in excavated soils and rocks.

For instance, Cossio et al. (2018) used the Jaw Crusher Retsch BB 200 equipped with stainless steel breaking jaws and variable openings to obtain a size reduction from $<90 \mathrm{~mm}$ down to $<2 \mathrm{~mm}$. Chatfield (2018) crushed by agate mortar and pestle the amphibole-containing material for TEM investigations (Transmission electron microscopy; ISO 13794 (1999)). In Baietto et al. (2019), samples were ground in an agate jar closed with a sealing gasket lid (model number 952/2 from Humboldt-Wedag).

Disk pulveriser, plate grinder cross beater, freezer mill or ball mill are also used too. Moreover, Salamatipour et al. (2016). showed that wet grinding preserved fibre integrity and originated individual fibrils with high aspect ratio, whereas dry grinding broke fibres, primarily creating fibre bundles with smaller aspect ratio.

Therefore, grinding is an extremely delicate stage and is often the reason for the scarce reliability of quantitative determinations based on counting of the number of fibres in asbestos containing materials (Cavariani et al., 2010).

\section{Materials and Methods}

\section{Materials}

In this research, six samples containing amphiboles (Fig. 1), from metamorphic units of ophiolitic and continental crust, have been selected. Three samples contain asbestiform amphiboles (F1, F2, F3) and three (P1, P2, P3) amphiboles with prismatic/acicular habit:

F1: amphiboles asbestos vein in ophicalcite outcropping in Ligurian Apennines (Italy)

F2: amphiboles asbestos vein in serpentinite nearby Ligurian Alps/ Apennines (Italy)

F3: coarse-grained amphibole asbestos vein in serpentinite of Ligurian Apennines (Italy)

P1: amphibole-bearing metagabbro coming from Ligurian Apennines (Italy)

P2: amphibole-bearing dolomite (Swiss Alps)

P3 amphibolite vein from Ligurian Alps (Italy)

\section{Sample Preparation and Analytical Methods}

Sample preparation and SEM analyses were carried out at the Department of Earth, Environment, and Life Sciences (DISTAV), University of Genoa, Italy.

Before proceeding with the comminution, preliminary observations on the asbestiform or non-asbestiform amphibole morphology (Fig. 2) were carried out by SEM-EDS (TESCAN Vega3 XML) under 2000x of magnification (Mag), $20 \mathrm{kV}$ of acceleration voltage (HV) and with back scattered electron as detector (Det).

The spectra obtained and consequently the elemental analysis of amphiboles were carried out by energy dispersive X-ray spettroscopy (Oxford Instruments X-MaxN 20) with AZtec 2.4 software.

Afterwards, each sample was divided into three aliquots of $3 \mathrm{~g}$ each and mechanically milled at three different time intervals ( 30 seconds, 120 seconds, 300 seconds respectively), at constant speed (Speed 2)
F1

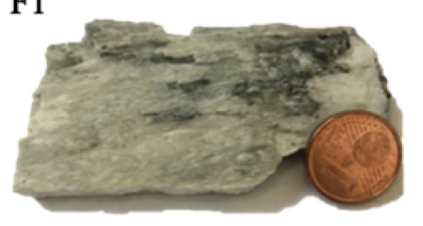

P1

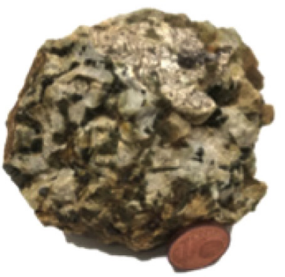

F2

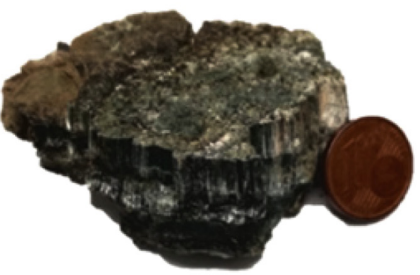

P2

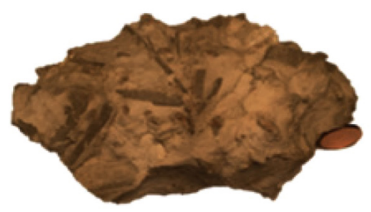

F3

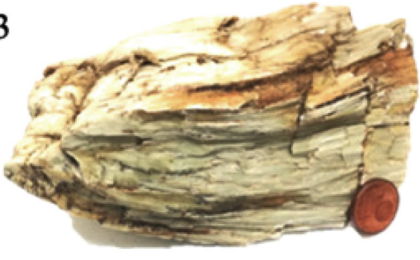

P3

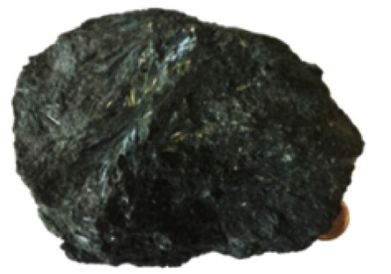

Figure 1. Photographs of the samples. F1, amphiboles vein in ophicalcite; F2, amphiboles vein in serpentinite; F3, amphiboles vein in serpentinite; P1, amphibole-bearing metagabbro; P2, amphibole-bearing dolomite; P3, amphibolite vein. 

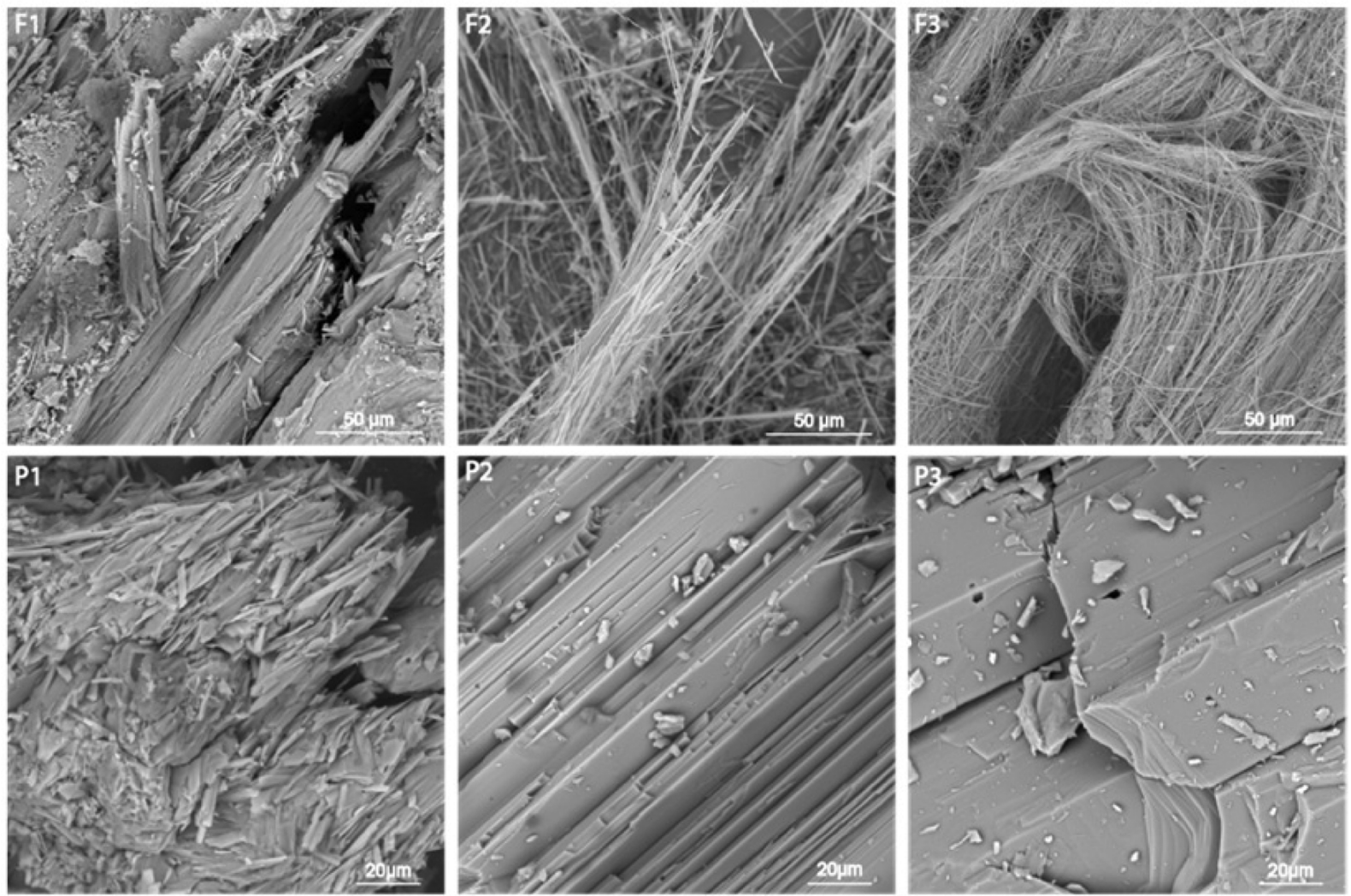

Figure 2. SEM images of asbestiform (F1, F2, F3) and non-asbestiform (P1, P2, P3) amphiboles (HV: 20 kV; Det: BSE).

with the Retsch-Mill McCrone micronizer equipped with a hermetically sealed case containing up to 48 small agate cylinders. A mechanical system moves the chamber so that the agate cylinders collide with each other and grind gently the sample.

After milling, all samples were sieved using a sieve with opening size of $0.106 \mu \mathrm{m}$ and then weighed. For each sample, $10 \mathrm{mg}$ of powder were weighed by analytical balance (RadwagAs 220.R2) and suspended in $100 \mathrm{ml}$ of deionized water. To improve the dispersion of the solution, the sample was left in an ultrasonic bath for $10 \mathrm{~min}$. Using a vacuum filtration system, a known aliquot of the prepared dispersion containing $\sim 1 \mathrm{mg}$ of powder was deposited (deposit ca. $0.1 \mathrm{mg}$ of the sample on the membrane) on a 47-mm-diameter polycarbonate membrane with a porosity of $0.8 \mathrm{~m}$. Subsequently, a quarter of each filter was mounted an aluminium stub (sample holder) using a conductive glue (carbon tape). The filter was coated with a $25-50 \mathrm{~nm}$ thick Au layer by cathodic sputtering (Quorum Q150T ES).

General and preliminary observations were made at 1000x magnification. The measurements of the fibres and therefore the counts were made at 2000x magnification, by analysing an area of $2 \mathrm{~mm}^{2}$, in accordance with the guidelines drawn up in the Italian M. D. 06/09/1994.

Both length and diameter were measured for each particle. We observed the morphology and geometric properties in each sample. Then, a comparison of lengths, widths and aspect ratio was carried out.

In order to check the statistical reliability of the data, the one-way Analysis of Variance (ANOVA) was addressed to verify the internal variability within each group. In particular, we compared the populations of amphiboles (in detail: P1-P2-P3 and F1-F2-F3), that are supposed to have similar aspect ratio (length divided by the width), ground in the three different time intervals $(30,120$ and 300 seconds respectively). Statistical significance was determined by a significance level (p-value) $<0.05$.

\section{Results and Discussion}

Under SEM, the samples were univocally divided into two categories. In F1, F2 and F3, amphiboles occur as bundles formed by flexible fibrils, stretched and parallel. In P1, P2 and P3, amphiboles occur as prismatic/acicular crystals with the typical planar surfaces leading to separation like splinters with the geometric ratios of regulated fibres.

From a mineralogical point of view, asbestiform (Fig. 3) and nonasbestiform samples (Fig. 4) contain amphiboles belonging to the actinolite-tremolite series. Samples F1, F2, F3 show a mineral chemistry composition closer to the tremolite end-member. Samples F1 and F3 have a slightly higher iron content, while sodium in F2 make these amphiboles closer to the composition of actinolite.

Samples P1, P2, P3 also show oxide composition closer to ideal tremolite. However, in P1 the sodium concentration approaches the actinolite end-member and $\mathrm{P} 2$ and $\mathrm{P} 3$ have a high content in iron and sodium. The amphiboles of these samples have a mixed composition typical of this solid solution.

The results show that when asbestiform and non-asbestiform tremolite-actinolite are present, they occur in all samples representative of the three different grinding times. The morphological differences and the distinct distribution of length:width ratio of the particles (Fig. 5) confirm that the two groups behave very differently during comminution. 

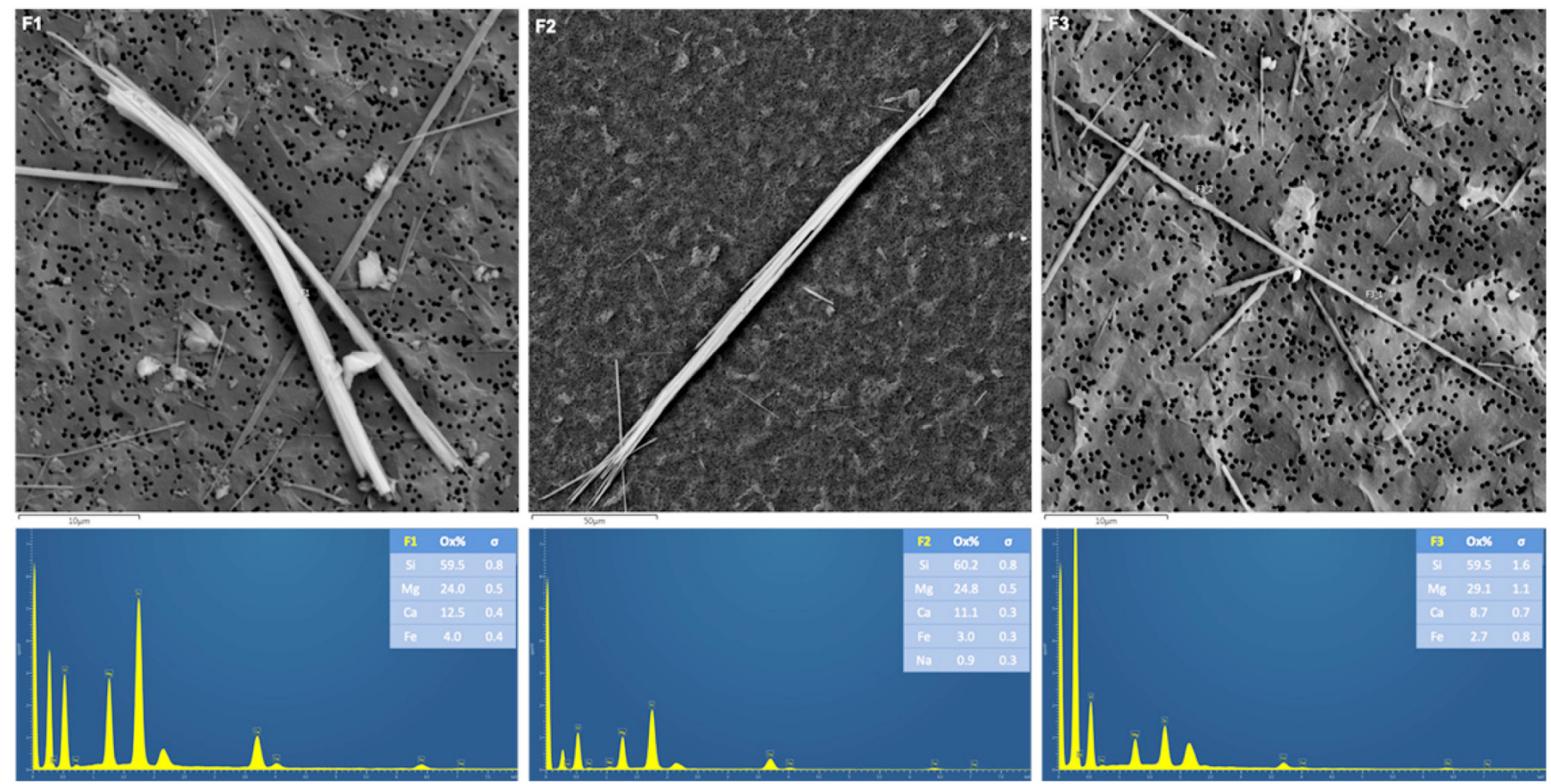

Figure 3. SEM images of asbestiform amphiboles (F1, F2, F3) and their relative elemental analysis (HV: $20 \mathrm{kV}$; Det: BSE and EDS). The results are shown as percentage in oxides (Ox\%). The statistical error is displayed as sigma ( $\sigma)$, which represents the overall confidence figure for the analysis, especially when an element is present at low concentration.
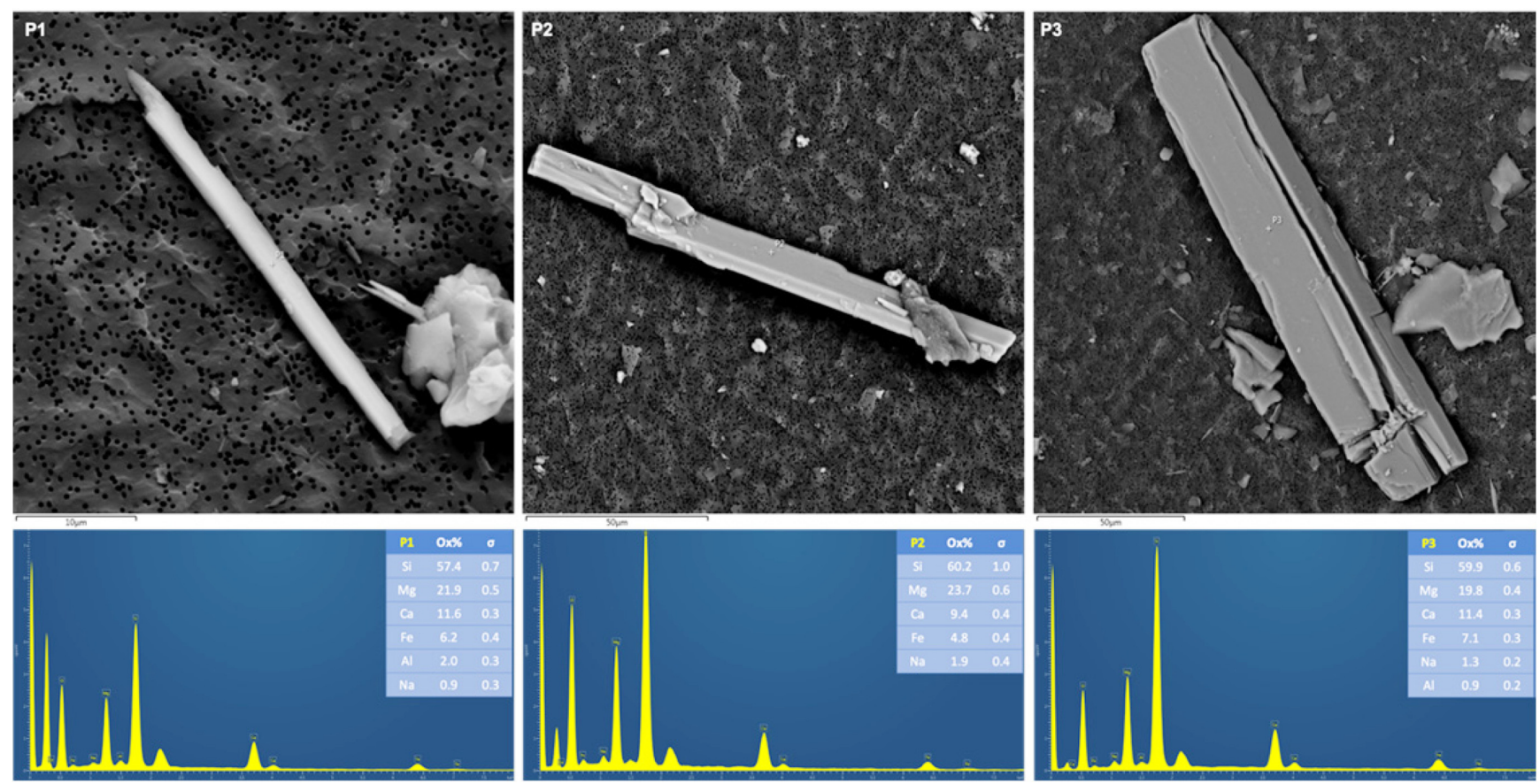

Figure 4. SEM images of non-asbestiform amphiboles (P1, P2, P3) and their relative elemental analysis (HV: $20 \mathrm{kV}$; Det: BSE and EDS). The results are shown as percentage in oxides $(O x \%)$. The statistical error is displayed as sigma $(\sigma)$, which represents the overall confidence figure for the analysis, especially when an element occurs at low concentration.

The average aspect ratio of asbestos particles is larger than that observed for prismatic/acicular amphiboles. Asbestiform amphiboles show an average aspect ratio values ranging from 15:1 to $65: 1$. The major frequency ranges between 30:1 to $35: 1$ (more than 30\%). Nonasbestiform amphiboles demonstrate an average aspect ratio values ranging from $3: 1$ to 20:1, with prevalent frequency $8: 1$ ( $\sim 5 \%)$.
Only samples with non-asbestiform amphiboles (P1-P2-P3) ground for 30 and 300 seconds have a p-value higher than 0.05 , which means there are no statistically significant differences. In the case of the other samples, regardless if asbestiform or non-asbestiform amphiboles, they showed a p-value lower than 0.05 . A summary of means, standard deviations for the aspect ratio of the particles and the statistical data is shown 

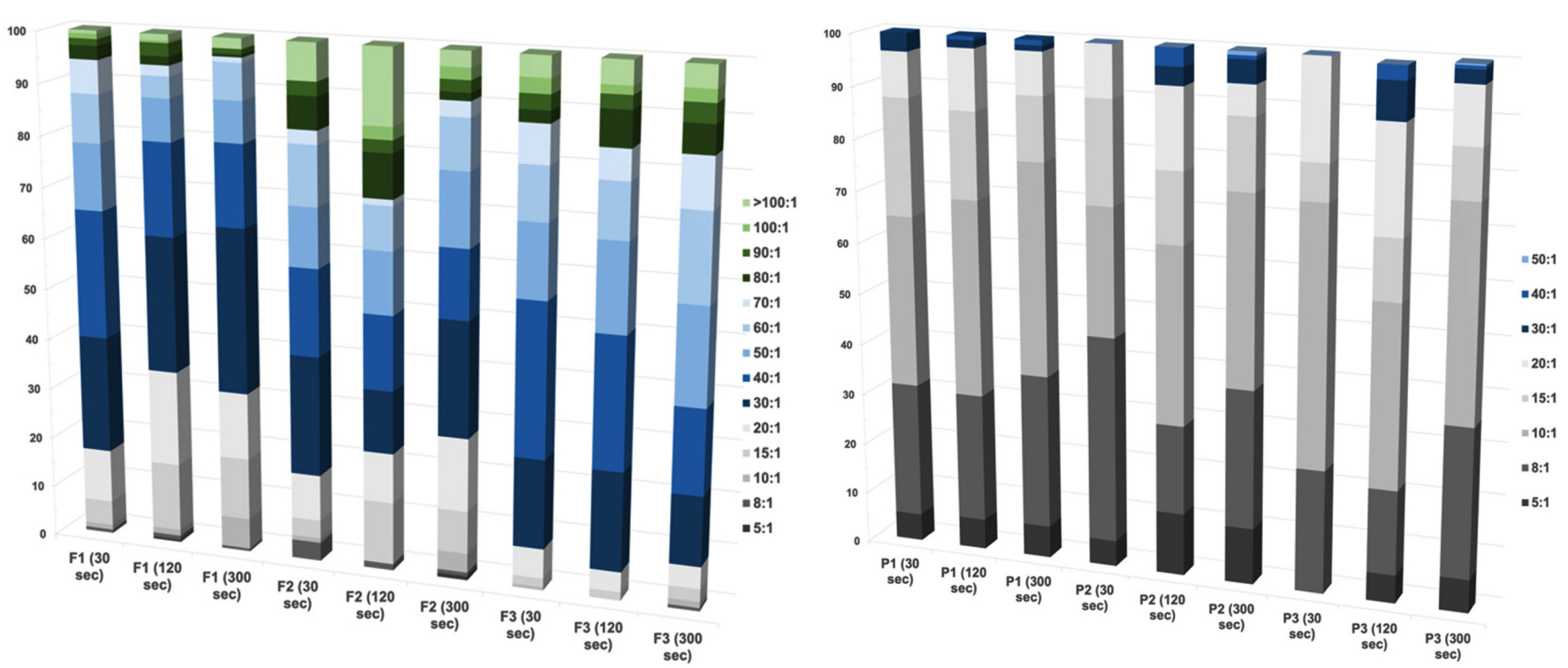

Figure 5. Illustrative histograms of the frequency (expressed as a percentage) of the different length:width ratios of the particles present in the samples (P1, P2, P3, F1, F2 and F3) for the three different grinding times (30, 120 and 300 seconds).

Table 2. Number of particles $(N)$ detected in the different samples at different grinding times. Values represent Mean of each aspect ratio (A/R Mean), standard deviation (SD) and P-value

\begin{tabular}{|c|c|c|c|c|c|}
\hline Milling time & Sample & $\mathrm{N}$ & $\mathrm{A} / \mathrm{R}$ mean $(\mu \mathrm{m})$ & SD & P-Value \\
\hline \multirow{6}{*}{$30 \mathrm{sec}$} & P1 & 57 & 7.01 & 3.32 & \multirow{3}{*}{$>0.05$} \\
\hline & $\mathrm{P} 2$ & 20 & 6.46 & 2.57 & \\
\hline & P3 & 42 & 7.02 & 2.57 & \\
\hline & $\mathrm{F} 1$ & 305 & 37.24 & 18.89 & \multirow{3}{*}{$<0.05$} \\
\hline & $\mathrm{F} 2$ & 111 & 44.05 & 30.14 & \\
\hline & F3 & 173 & 44.54 & 24.12 & \\
\hline \multirow{6}{*}{$120 \mathrm{sec}$} & $\mathrm{P} 1$ & 136 & 6.83 & 3.13 & \multirow{3}{*}{$<0.05$} \\
\hline & $\mathrm{P} 2$ & 58 & 7.53 & 4.54 & \\
\hline & P3 & 111 & 9.11 & 6.81 & \\
\hline & F1 & 240 & 30.91 & 20.28 & \multirow{3}{*}{$<0.05$} \\
\hline & F2 & 82 & 52.28 & 40.63 & \\
\hline & F3 & 307 & 47.18 & 26.20 & \\
\hline \multirow{6}{*}{$300 \mathrm{sec}$} & P1 & 97 & 6.44 & 2.99 & \multirow{3}{*}{$>0.05$} \\
\hline & $\mathrm{P} 2$ & 138 & 6.73 & 4.67 & \\
\hline & P3 & 313 & 6.77 & 3.72 & \\
\hline & $\mathrm{F} 1$ & 198 & 29.86 & 19.08 & \multirow{3}{*}{$<0.05$} \\
\hline & $\mathrm{F} 2$ & 133 & 38.58 & 31.14 & \\
\hline & F3 & 164 & 48.95 & 25.88 & \\
\hline
\end{tabular}

in Table 2.

Generically, a slight deviation of the 30 sec time length curves from the other ones is evidenced. By extending the time of grinding, a comparison between the trends of the other two groups show no significant difference. This applies both to specimens with asbestiform amphiboles and to specimens with non-asbestiform amphiboles (Fig. 6).

The length but also the diameter of the asbestiform amphiboles tend to decrease rapidly in the early stages of comminution while, on the contrary, the length of the prismatic tremolite varies rather uniformly throughout the milling process.
Furthermore, for each grinding time, the granulometric range of the fibres was determined. As the grinding time increases, asbestiform amphiboles tend to have a more homogeneous distribution (Fig. 7) in terms of width. The number of countable fibres decreases, because many turned below the detectable dimensions at 2000x of magnification (fibrils reached a diameter even lower than 0.2-0.1 $\mu \mathrm{m}$ ). As a rule, length does not seem affected by the milling, therefore it tends to remain more or less constant.

Conversely, in the case of non-asbestiform amphiboles, at increasing grinding time, a greater dispersion of width is evidenced (Fig. 7). 
F1
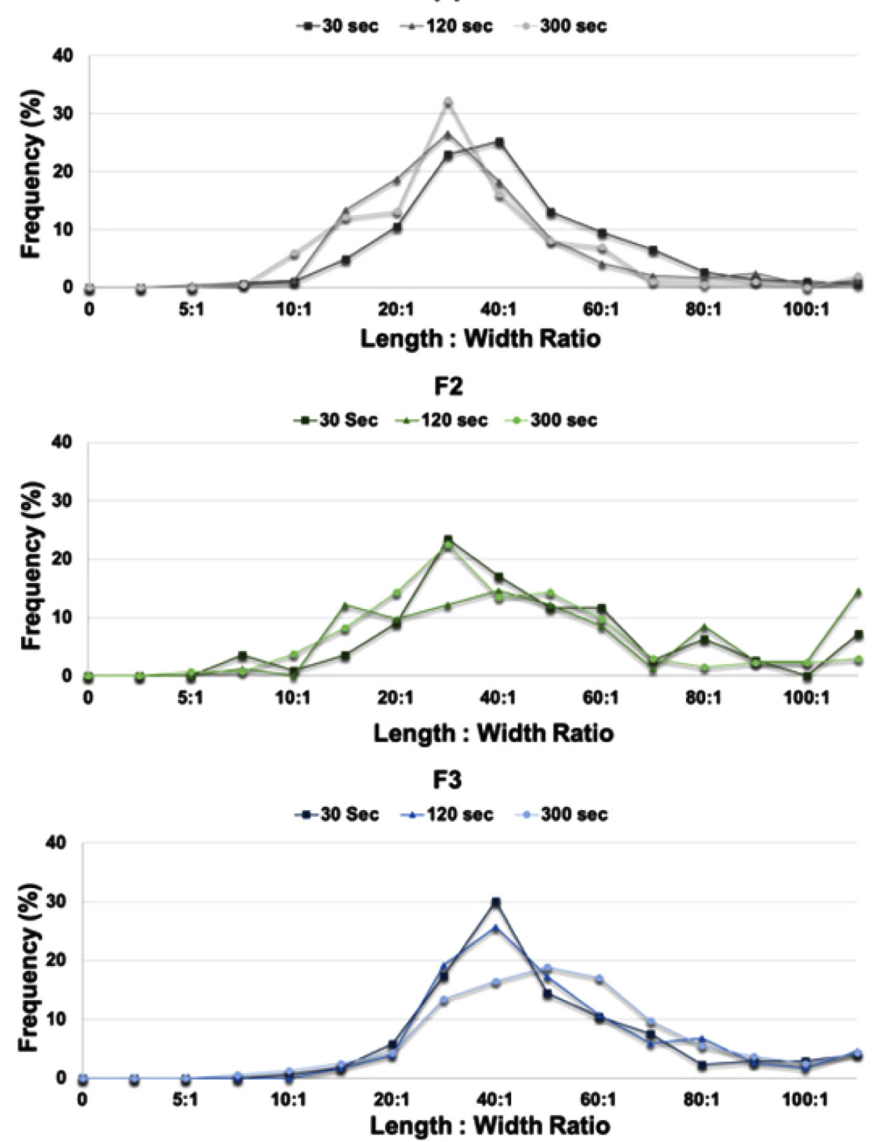
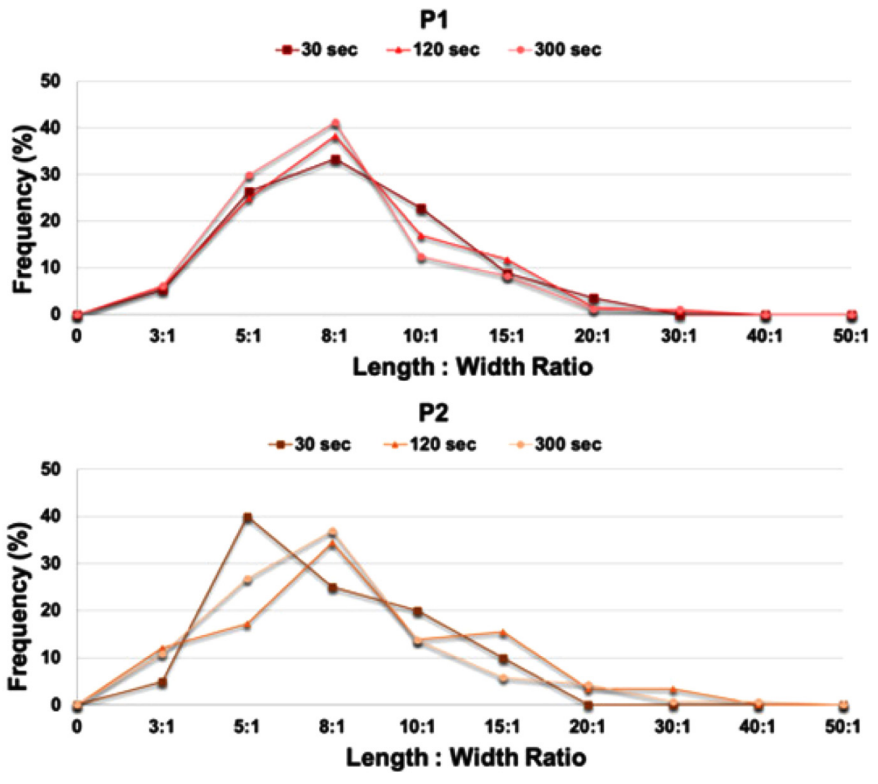

P3

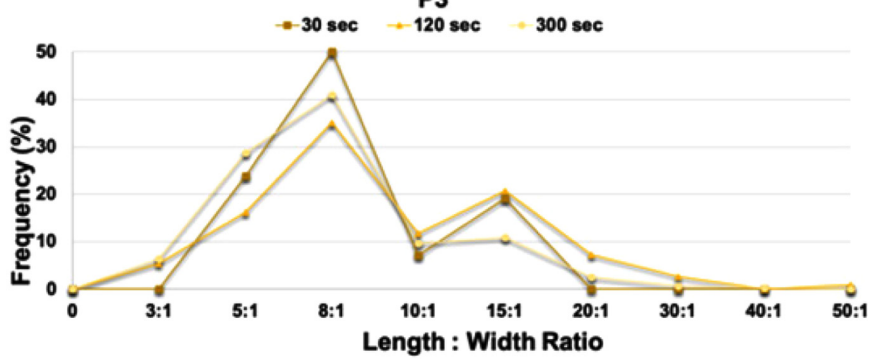

Figure 6. Comparison of the aspect ratio distribution, in the three different intervals of grinding times, of asbestiform (F1, F2, F3) and nonasbestiform (P1, P2, P3) amphiboles.

The number of fibres increases after longer milling time because they separate, producing cleavage fragments. However, the particles shorten considerably in length but also in the diameter, as the width is not below $0.6-0.5 \mathrm{~mm}$.

In non-asbestiform samples, after $30 \mathrm{sec}$ of milling, some fragments were not counted since they did not respect the geometric ratios.

Finally, the aspect ratios $v s$. the diameters of the asbestiform amphiboles (samples F1, F2 and F3), were compared with those of nonasbestiform amphiboles (samples P1, P2 and P3). using a chart as in Van Orden et al. (2009). This graph unequivocally highlights that, even after the comminution, the two type of samples show distinct, differences in distribution. However, the distinction is not absolute because some asbestos amphiboles fall below the minimum aspect ratio, while some non-asbestiform particles exceed even greatly the 20: 1 aspect ratio (Fig. 8).

\section{Conclusions}

1. Preliminary results show differences between asbestiform and non-asbestiform amphiboles confirmed in a distinct distribution length: width ratio of fibres, as effect of the comminution. In both cases, small distinctions are observed between the samples ground for 30 seconds compared with the others. Between 120 seconds and 300 seconds of milling, prismatic and asbestos amphiboles do not show significant differences. However, the one-way analysis of variance (ANOVA) highlighted statistically significant differences also in this regard.

2. In order to obtain comparable quantitative results, our data strongly support the need to select the same equipment in each laboratory and standardize the method of sample preparation. Comminution is a critical phase in the preparation of the samples: the shape of produced particles depends on host lithology, type of the machine (in particular the specific breakage mechanism in the grinding device), time of milling applied to the sample and the relative application of the stress.

3. Moreover, the geometric overlap of particle sizes could cause an incorrect classification, unacceptable because it can lead to over- or underestimation of the concentrations, and therefore of the risk. Although all asbestos amphiboles have been banned, their non-asbestiform analogues whose geometric ratios fall within the definition of fibres are not yet univocally regulated as asbestos. We demonstrated that, under the same chemical composition, the morphological characterization of the phases cannot be disregarded for the evaluation of carcinogenicity.

4. Exposition to asbestos may cause adverse effects, but a clear relationship between mineralogy and texture of fibres $v s$. toxicity is still lacking. Although this topic still remains liable to be integrated with future contributions, a worldwide gap in the science of disease prevention is open. This work provided experimental evidence on the 

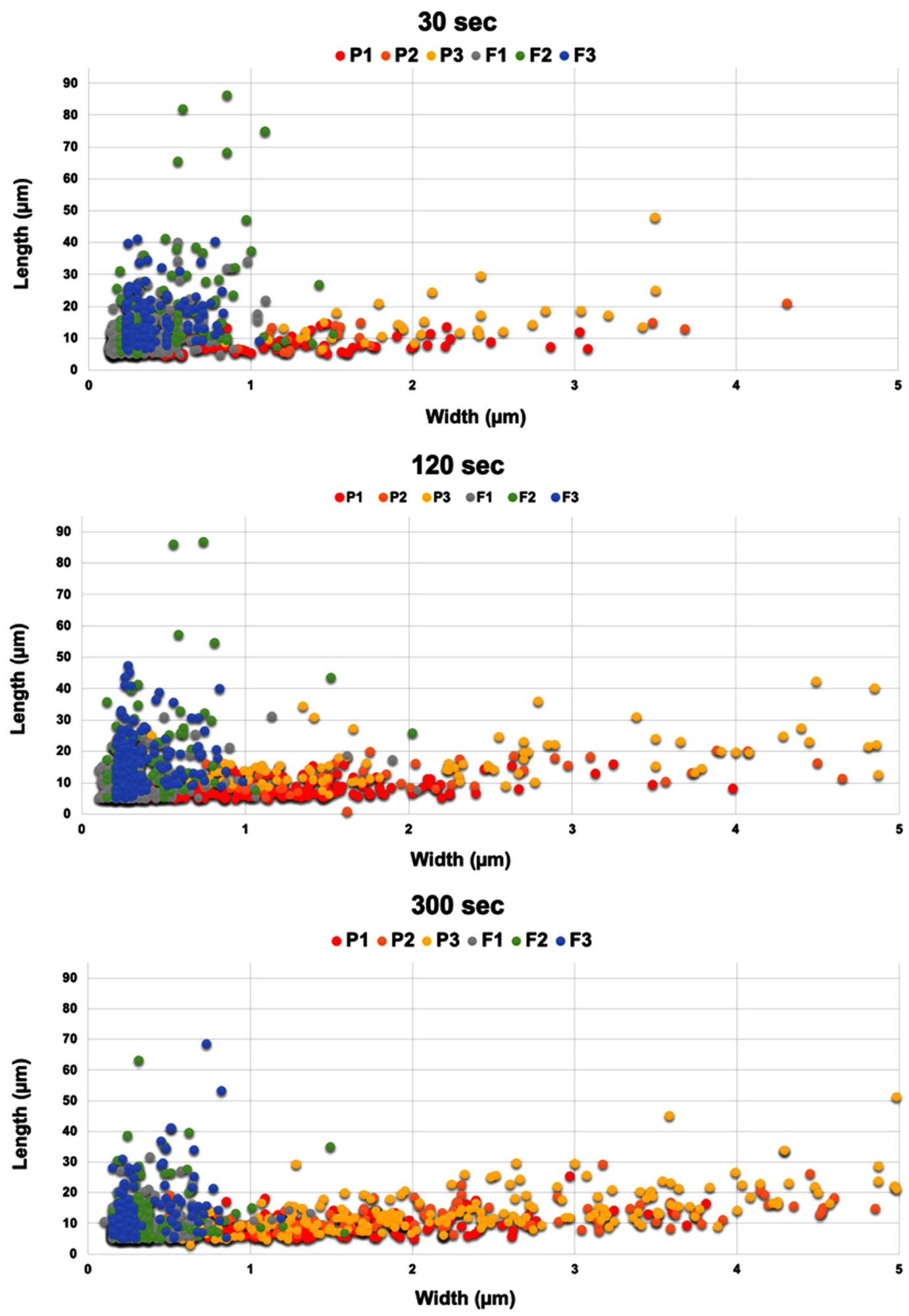

Figure 7. Influence of milling time (30, 120, 300 seconds respectively) on length and width dimensions of particles.

behaviour of non-asbestiform amphiboles under different comminution conditions. More data on the shape and the size particles are the benchmark to new perspectives into the study of morphologic features and of mutagenic mechanisms of a presently misunderstood material.

It has been clearly shown that the procedure for discriminating asbestos from cleavage fragments and prismatic crystals was not effective across all (Harper et al., 2012). Moreover, both asbestiform and non-asbestiform amphiboles (Gamble and Gibbs, 2008; Addison and McConnel, 2008) may show inhalable elements with width $<3$ micron, length $>5$ micron and aspect ratio $>1: 3$, whose dangerousness could be different, presently object of epidemiologic studies (Gualtieri, 2017). 


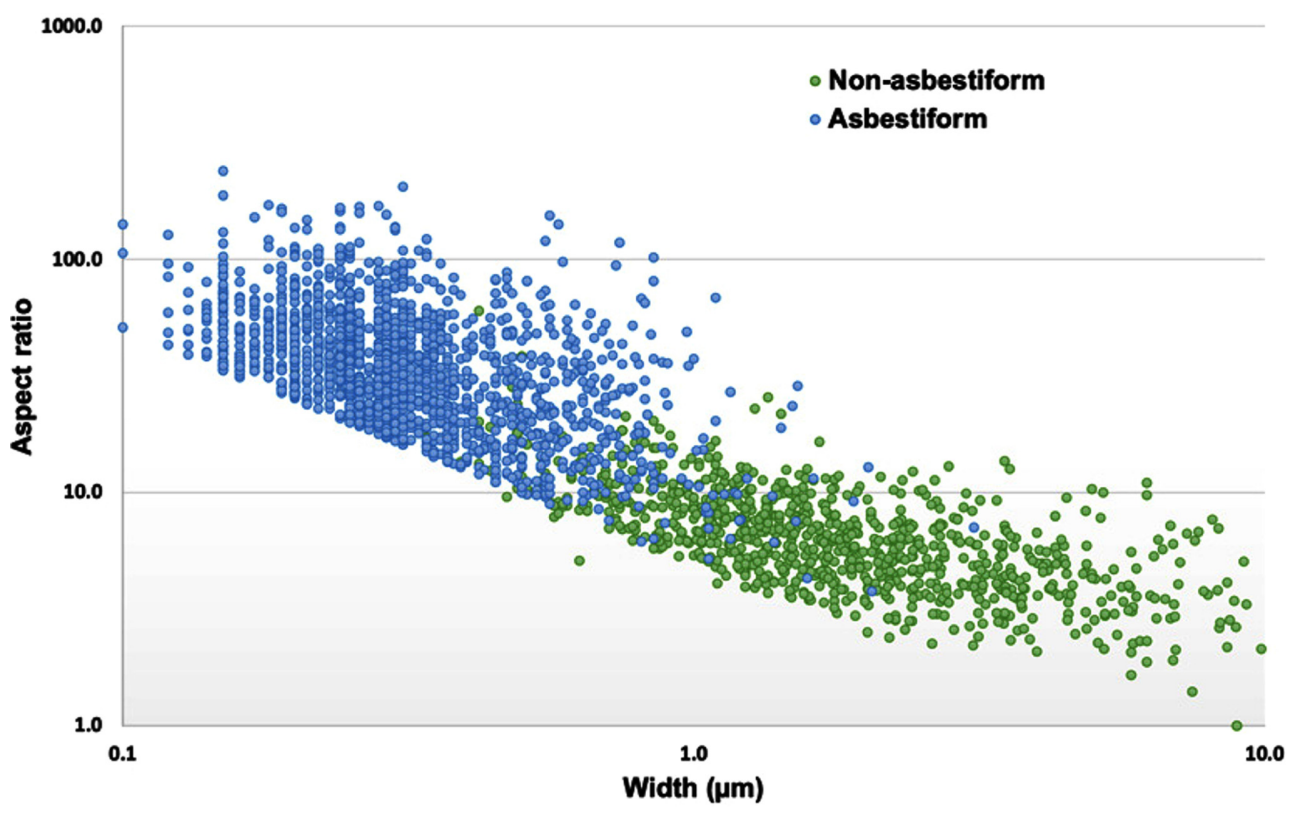

Figure 8. Relationship between width and aspect ratio (logarithmic scale) for asbestiform and non-asbestiform amphiboles.

\section{Acknowledgements}

This work was carried out with the financial support of the Analisi delle proprietà microstrutturali, chimico-fisiche di materiali inorganici; determinazioni quantitative della composizione mineralogica di materiali naturali e delle proprietà tecniche dei materiali litici Laboratory funds, DISTAV, University of Genoa.

\section{References}

Addison, L., and McConnel, E.E. 2008, A review of carcinogenicity studies of asbestos and non-asbestos tremolite and other amphiboles. Regulatory Toxicology and Pharmacology, v. 52/1, S187-S199. doi:org/10.1016/ j.yrtph.2007.10.001.

AHERA (Asbestos Hazardous Emergency Response Act), 1987, Interim transmission electron microscopy analytical methods - mandatory and non-mandatory - and mandatory section to determine completion of response. Federal Register, v. 52, pp. 41857-41897, October 30.

Baietto, O., Diano M., Zanetti G., and Marini P., 2019, Grinding Test on Tremolite with Fibrous and Prismatic Habit. Fibers, v. 7, pp. 52-67. doi:org/10.3390/fib7060052.

Belardi, G., Vignaroli, G., Trapasso, F., Pacella, A., and Passeri, D., 2018, Detecting asbestos fibres and cleavage fragments produced after mechanical tests on ophiolite rocks: clues for the asbestos hazard evaluation. Journal of Mediterranean Earth Sciences v. 10, pp. 6378. doi:org/10.3304/JMES.2018.016.

Berman D.W., and Crump K.S., 2003. Final draft: Technical support document for a protocol to assess asbestos-related risk. Prepared for Office of Solid Waste and Emergency Response, U.S. Environmental Protection Agency, Washington, DC.20460, USEPA \#9345.4-06 October 2003.

Bloise, A., Catalano, M., and Gualtieri, A.F., 2018, Effect of Grinding on Chrysotile, Amosite and Crocidolite and Implications for Thermal Treatment. Minerals, v. 8, pp. 135-152. doi:org/10.3390/min8040135.

Cavariani, F., Marconi, A., and Sala, O., 2010, Asbestos: sampling, analytical techniques and limit values. 549 Ital. Journal of occupational and environmental hygiene. v. 1, pp. 18-28.

Chatfield, E.J., 2008, A procedure for quantitative description of fibrosity in amphibole minerals. In 2008 Johnson Conference: Critical Issues in Monitoring Asbestos, ASTM International, Burlington, Vermont, July 14-July 18, 2008. Available at: www.astm.org.

Chatfield, E.J., 2018, Measurement of elongate mineral particles: What we should measure and how do we do it? Toxicology and Applied Pharmacology v. 361, pp. 36-46. doi:org/10.1016/j.taap.2018.08.010.

Cossio, R., Albonico, C., Zanella, A. Fraterrigo-Garofalo, S., Avataneo, Chiara, Compagnoni, R., and Turci, F. 2018, Innovative unattended SEM-EDS analysis for asbestos fiber quantification. Talanta v. 190, pp. 158-166. doi:org/10.1016/j.talanta.2018.07.083.

EPA (Environmental Protection Agency): Method for Determination of Asbestos in Bulk Building: Materials Perkins RL, Harvey BW: Method for the determination of asbestos in bulk building materials: 1993, U.S. Environmental Protection Agency EPA/600/R-93/116, Office of Research and Development, Washington, D.C.

Gaggero, L., Sanguineti, E., Yus González, A., Militello, GM., Scuderi, A., and Parisi, G., 2017, Airborne asbestos fibres monitoring in tunnel excavation. Journal of Environmental Management, v. 196, pp. 583-593. doi:org/ 10.1016/j.jenvman.2017.03.055.

Gamble, J.F., and Gibbs, G.W., 2008, An evaluation of the risks of lung cancer and mesothelioma from exposure to amphibole cleavage fragments. Regulatory Toxicology and Pharmacology. v. 52, S154-S186. doi:org/10.1016/j.yrtph.2007.09.020.

Gualtieri, A.F., 2017, Mineral fibres: Crystal chemistry, chemical-physical properties, biological interaction and toxicity. Volume 18 EMU Notes, 536 pp., ISBN: 9780903056656.

Ham, S., Hwang, S., and Yoon, C., 2019, Comparison of Methods for Pretreatment and Quantification of Bulk Asbestos Samples for Polarized Light Microscopy Analysis to Evaluate Asbestos-Containing Waste. Sustainability, v. 11, pp. 6440-6453. doi:org/10.3390/su11226440.

Harper, M., Lee, E.G., Doorn, S.S., and Hammond, O., 2008, Differentiating non-asbestiform amphibole and amphibole asbestos by size characteristics. Journal of Occupational and Environmental Hygiene, v. 5, pp. 761-770. doi:org/10.1080/15459620802462290.

Harper, M., Lee, E.G., Slaven, J., and Bartley, D., 2012, An inter-laboratory study to determine the effectiveness of procedures for discriminating amphibole asbestos fibers from amphibole cleavage fragments in 
fiber counting by phase-contrast microscopy. Annals of Occupational Hygiene, v. 56, pp. 645-659. doi:org/10.1093/annhyg/mer123.

Harris, K.E., Bunker, K.L., Strohmeier, B.R., Hoch, R., and Lee, R.J., 2007, Discovering the True Morphology of Amphibole Minerals: Complementary TEM and FESEM Characterization of Particles in Mixed Mineral Dust. RJ Lee Group, Inc., 350 Hochberg Road, Monroeville, PA, 15146, USA Modern Research and Educational Topics in Microscopy. A. Méndez-Vilas and J. Díaz (Eds.).

Hwang, J., Ramachandran, G., Raynor, P.C., Alexander, B.H., and Mandel, J.H., 2014, The Relationship Between Various Exposure Metrics for Elongate Mineral Particles (EMP) in the Taconite Mining and Processing Industry. Journal of Occupational and Environmental Hygiene, v. 11/9, pp. 613-624. doi:org/10.1080/15459624.2014.890287.

ISO (International Organization for Standardization), 1999. ISO 13794. Ambient air - Determination of asbestos fibres - Indirect-transfer transmission electron microscopy method.

Italian Ministerial Decree No. 06/09/1994. All. 1B- Quantitative determination of asbestos in bulk samples.

Keane, M.J., Stephens, J.W., Zhong, B.Z., Miller, W.E., and Wallace, W.E., 1999, A study of the effect of chrysotile fiber surface composition on genotoxicity in vitro. Journal of Toxicology and Environmental Health, Part A, v. 57/8, pp. 529-541. doi:org/10.1080/009841099157494.

Militello, G.M., Bloise, A., Gaggero, L., Lanzafame, G., and Punturo, R., 2019a, Multi-Analytical Approach for Asbestos Minerals and Their Non-Asbestiform Analogues: Inferences from Host Rock Textural Constraints. Fibers, v. 7, p. 42. doi:org/10.3390/fib7050042.

Militello, G.M. Sanguineti, E., Yus González, A., Mantovani, F., and Gaggero, L. 2019b, The Concentration of Asbestos Fibers in Bulk Samples and Its Variation with Grain Size. Minerals 2019, v. 9, pp. 539-558. doi:org/10.3390/min9090539.

NIOSH (National Institute for Occupational Safety and Health), 2011. Asbestos fibers and other elongate mineral particles: state of the science and roadmap for research. DHHS Publication No. 2011-159.

OSHA (Occupational Safety and Health Administration), 1994a. Rules and Regulations, Department of Labor: 29 CFR Parts 1910, 1915 and 1926, 59 FR 40964, RIN: 1218-AB25; Occupational Exposure to Asbestos; August 1994-Final Rule; Appendix B of 1910.1001; 1. Introduction.

OSHA (Occupational Safety and Health Administration), 1994b. Rules and Regulations, Department of Labor: 29 CFR Parts 1910, 1915 and 1926, 59 FR 40964, RIN: 1218-AB25; Occupational Exposure to Asbestos; August 1994-Final Rule; Appendix K of 1915.1001; Polarized Light Microscopy of Asbestos. 3.5 Analytical Procedure. 4.

Salamatipour, A., Mohanty, S.K., Pietrofesa, R.A., Vann, D.R., Christofidou-Solomidou M., and Willenbring, J.K., 2016, Asbestos Fiber Preparation Methods Affect Fiber Toxicity. Environmental Science and Technology Letters, v. 3, pp. 270-274. doi:org/10.1021/acs.estlett.6b00174.

Stanton, M.F., Layard, M., Tegeris, A., Miller, E., May, M., Morgan, E., and Smith, A., 1981, Relation of particle dimension to carcinogenicity in amphibole asbestos and other fibrous minerals. Journal of the National Cancer Institute, v. 67, pp. 965-976

Vallero, D.A. Asce, M., and Beard, M.E., 2009, Selecting Appropriate Analytical Methods to Characterize Asbestos in Various Media. Practice periodical of hazardous, toxic, and radioactive waste management, $\mathrm{v}$. 13/4, pp. 249-260. doi:org/10.1061/(ASCE)1090-025X(2009)13:4(249).

Van Orden, D.R., Allison, K.A., and Lee R.J., 2008, Differentiating amphibole asbestos from non-asbestos in a complex mineral environment. Indoor and Built Environment, v. 17, pp. 58-68. doi:org/10.1177/ 1420326X07087006.

Van Orden, D.R., Lee, R.J., Allison, K.A., and Addison J., 2009, Width distributions of asbestos and non-asbestos amphibole minerals. Indoor and Built Environment, v. 18, pp. 531-540. doi:org/10.1177/1420326X09341503.
Williams, C., Dell, L., Adams, R., Rose, T., and Van Orden, D., 2013, State-ofthe-science assessment of non-asbestos amphibole exposure: is there a cancer risk? Environmental Geochemistry and Health, v. 35, pp. 357 377. doi:org/10.1007/s10653-012-9500-0.

WHO (World Health Organization), 1997. The world health report 1997 conquering suffering, enriching humanity.

Wylie, A.G., Bailey, K.F., Kelse, J.W., and Lee, R.J., 1993, The importance of width in asbestos fiber carcinogenicity and its implications for public policy. American Industrial Hygiene Association Journal; Akron v. 54, Fasc. 5, (May 1993): p. 239. doi:org/10.1080/15298669391354621.

Wylie, A.G., Virta, R.L., and Russek, E., 1985, Characterizing and discriminating airborne amphibole cleavage fragments and amosite fibers: implications for the NIOSH method. American Industrial Hygiene Association Journal, v. 46, pp. 197-201. doi:org/10.1080/15298668591394653.

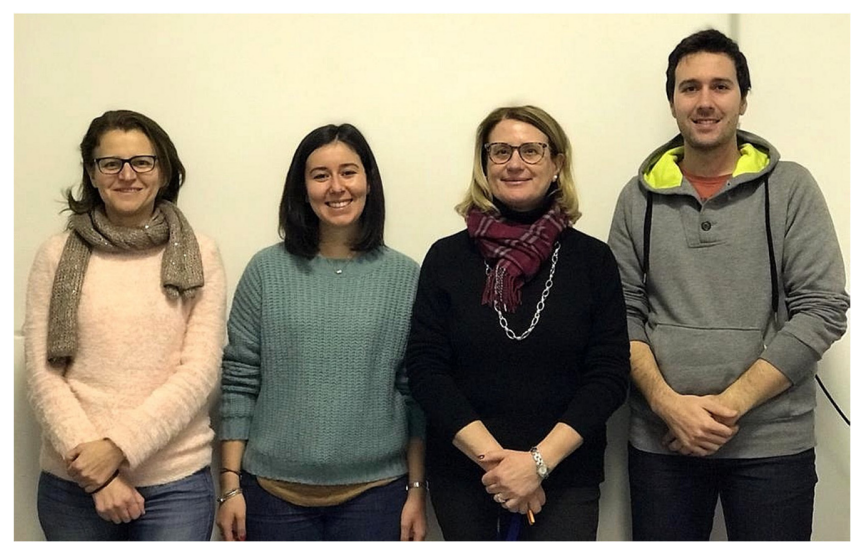

Elisa Sanguineti Master degree in Environmental Sciences, $\mathrm{PhD}$ in applied botanics at the University of Genoa. Since 2014, research fellow implementing the determination of asbestos fibers concentration in the air and excavated soils and rocks, by different techniques, in particular by Scanning Electron Microscopy. (SEM-EDS). Currently heading at the Laboratory of Electron Microscopy at DISTAV-UNIGE the asbestos monitoring task related with the railway tunneling across the Ligurian Alps "Terzo Valico dei Giovi".

Gaia M. Militello Master degree in Geological Sciences at Catania University. Research fellow implementing the determination of asbestos fibers concentration in the air and excavated soils and rocks in the asbestos monitoring task related with the railway tunneling across the Ligurian Alps "Terzo Valico dei Giovi". Since 2017, PhD student at the University of Genoa, currently investigating Naturally Occurring Asbestos and related environmental and biological problems.

Laura Gaggero Master degree in Geological Sciences, PhD in Earth Sciences, Professor of Applied Petrography at the University of Genoa. Laura has published more than 120 articles on Paleozoic petrology and geodynamics, on Archeometry and Applied petrography. Project manager / principal investigator of EU and national projects. Head of the Laboratory of Electron Microscopy at DISTAV-UNIGE. Currently coordinating at the Laboratory of Electron Microscopy at DISTAV-UNIGE the asbestos monitoring task related with the tunneling across the Ligurian Alps "Terzo Valico dei Giovi".

Adrián Yus González Master degree in Geological Sciences at Zaragoza University (Spain). Since 2016 research fellow implementing the determination of asbestos fibers concentration in the air and excavated soils and rocks, by different techniques, in particular by Scanning Electron Microscopy. (SEM-EDS). Currently implementing at the Laboratory of Electron Microscopy at DISTAV-UNIGE the asbestos monitoring task related with the railway tunneling across the Ligurian Alps "Terzo Valico dei Giovi". 